\title{
MEMÓRIAS SENTIMENTAIS (E CRÍTICAS) DE UM PROGRAMA DE INICIAÇÃO À DOCÊNCIA: O PONTO DE VISTA DO PIBID HISTÓRIA UFF 2014
}

\author{
Everardo Paiva de Andrade ${ }^{\mathrm{i}}$
}

\begin{abstract}
Resumo: O presente trabalho reflete, antes de mais nada, o modo de inserção de um coordenador de área do PIBID no próprio Programa e a maneira pela qual ele produz sentidos, se apropria e compartilha significados coletivamente mobilizados. Discute a formação de professores sob a perspectiva estratégica da iniciação à docência como eixo articulador e finalidade principal do PIBID. Sugere que o Programa agrega valores novos à formação implementada pelos cursos de licenciatura em ambiente universitário, tradicionalmente subordinados ao bacharelado, tais como a centralidade da reflexão sobre a prática e o horizonte da educação e do ensino escolar. Conclui pela multiplicidade de PIBIDs em face da diversidade de experiências formativas vinculadas às áreas de conhecimento.
\end{abstract}

Palavras-chave: Cultura escolar. Formação de professores. Iniciação à docência. PIBID de História. Relação universidade / escola.

\section{SENTIMENTAL (AND CRITICAL) MEMORIES OF A TEACHING INITIATION EXPERIENCE}

\begin{abstract}
This work reflects, above all, the insertion mode of a PIBID area coordinator in the program itself and the way it produces senses, appropriates and shares collectively mobilized meanings. Discusses teacher training in the strategic perspective of initiation to teaching as its central theme and main purpose of PIBID. It suggests that the program adds new values to the training implemented by degree courses in university environment, traditionally subordinate to the baccalaureate, such as the centrality of reflection on practice and the horizon of education and school teaching. It concludes by the multiplicity of PIBIDs in the face of the diversity of training experiences related to knowledge areas.
\end{abstract}

Keywords: School culture. Teacher training. Introduction to teaching. PIBID of History. University / School relationship.

Porque nós, meus colegas, meus amigos, neste vale de emoções, de apogeus e de quedas de Ícaro, vivemos apenas o romance da eterna pesquisa, da eterna procura, da eterna recherche, da eterna mágoa da miragem!

(Oswald de Andrade, 1971, p. 88) 


\section{Prescrições e práticas pibidianas na UFF}

Uma das ações propostas no subprojeto construído pelos orientadores do PIBID Programa Institucional de Bolsas de Iniciação à Docência da área de História da UFF sugere que, ao licenciando, futuro professor de História, cabe

inteirar-se da execução de projetos e ações antirracistas pela escola, propondoos quando eles não existirem. Deve também observar estratégias de combate ao racismo nas aulas de História, relacionadas ou não aos conteúdos curriculares. Deve, enfim, observar etnograficamente as relações entre os sujeitos escolares, inspirando-se, sobretudo, nos documentos normativos.

A ação descrita na ementa acima, talvez de um modo excessivamente prescritivo, destina-se ao acompanhamento da Lei $\mathrm{n}^{\mathrm{o}} 11.645 / 2008$, propondo a criação do ORE Observatório das Relações Étnico-Raciais na Escola, no âmbito do projeto institucional com que a UFF concorreu ao edital nº 61, da Capes. Sua referência é a Portaria nº 96/2013, da mesma agência, que institui a edição do PIBID, iniciada no ano seguinte. No relatório produzido ao final do primeiro ano de atividades do PIBID, os bolsistas em uma das escolas parceiras assim descreveram as atividades desenvolvidas:

A partir de reflexões construídas ao longo do ano com os licenciandos buscando uma releitura do currículo escolar, de maneira a descentralizar a narrativa histórica da Europa, realizaram-se diversas atividades pedagógicas com toda a comunidade escolar, em especial com os jovens adolescentes do Ensino Médio, sobre os frequentes casos de preconceito enfrentados pelas populações negra e indígena em nossa sociedade. Todas as atividades orientaram-se no sentido de desconstruir visões estereotipadas e preconceituosas sobre as culturas e histórias afro-brasileiras, africanas e indígenas que ainda permeiam a sala de aula.

Avaliando os resultados alcançados, os mesmos bolsistas registraram no relatório que a

ação

ressignificou as identidades negras e indígenas junto aos estudantes da escola; sensibilizou os futuros docentes para a importância de abordar outras narrativas históricas nas aulas; valorizou a estética negra, diminuindo práticas preconceituosas na escola; sensibilizou a comunidade escolar para a necessidade de respeitar e valorizar a diversidade religiosa brasileira. 
Experiência talvez inédita no modo tradicional de formar professores da universidade brasileira, marcando as práticas universitárias com uma efervescente descoberta da escola como diferença e como alteridade dialógica, o PIBID corre o risco de ser arrastado na correnteza da crise política e econômica que assola o país, deixando para trás desalento e frustração, além de um rastro de relíquias e construções inacabadas.

\section{O PIBID entre concepções e práticas de formação}

A formação de professores nas áreas disciplinares, em cursos de licenciatura, no Brasil, parece admitir uma dupla abordagem em face do modo como se relaciona com o tempo. Uma delas, claramente diacrônica, permite compreender o quanto nos mantemos aderentes ou o quanto nos distanciamos daquele modelo genético de formação, que se poderia chamar de " $3+$ 1". Genético porque herdeiro direto do modo como se deu a instalação das faculdades de filosofia para a formação de professores em nível superior, nos anos da década de 1930. Com foco estrito no conhecimento e nas competências, muitos projetos de formação parecem desenhar sua estrutura curricular preservando, com maiores ou menores modificações, uma combinação alquímica de conhecimentos disciplinares numa área específica e formação pedagógica geral.

É preciso que se diga, porém, que nem toda formação particularmente interessada no conhecimento merece ser qualificada como de racionalidade técnica. Contreras (2002) discute autonomia de professores a partir das articulações entre aspectos da profissionalidade docente, desentranhando os modelos teóricos de compreensão da prática profissional com base em concepções de professor como profissional reflexivo ou como intelectual crítico a partir da crítica ao modelo do especialista técnico. Monteiro (2000), por outro lado, analisa perspectivas não tecnicistas para o estágio supervisionado de licenciandos de história, baseadas numa problemática dos saberes (escolar, docente), partindo do princípio de que a escola é um espaço de produção - e não meramente de reprodução - de saberes, de grande interesse para a formação inicial docente.

Outra abordagem é aquela que se liga ao tempo vivido, centrada no sujeito da formação, em sua história de vida e em seu desenvolvimento profissional, isto é, nas experiências desenvolvidas ao longo da vida, definindo seu projeto com base no interesse pelo processo por 
meio do qual alguém se torna professor. Nessa perspectiva, como afirma Maurice Tardif (2002: 108-109), o tempo:

não é somente um meio - no sentido de meio marinho ou terrestre - no qual se encontram mergulhados o trabalho, o trabalhador e seus saberes; também não é unicamente um dado objetivo caracterizado, por exemplo, pela duração administrativa das horas ou dos anos de trabalho. É também um dado subjetivo, no sentido de que contribui poderosamente para modelar a identidade do trabalhador. (...) A própria noção de experiência, que está no cerne do Eu profissional dos professores e de sua representação do saber ensinar, remete ao tempo, concebido como um processo de aquisição de um certo domínio do trabalho e de um certo conhecimento de si mesmo.

Nesse sentido, diversas interpretações sugerem que se reflita sobre a relação entre distintas experiências temporais, nos percursos prévios de história de vida, na formação como na profissão. António Nóvoa (2011, p. 535), por exemplo, interessado na materialização prática de formulações discursivas a respeito da aprendizagem docente e do desenvolvimento profissional, sugere que se passe "a formação de professores para dentro da profissão", não no sentido de esvaziar a discussão teórica necessária ao trabalho docente, mas de garantir que tais discussões articulem a formação tanto à história de vida quanto ao mundo do trabalho, evitando perder-se no labirinto da formalização e redução da complexidade do ensino, no esvaziamento do contexto real de seu exercício e na idealização dos sujeitos e, sobretudo, do contexto escolar (Gauthier et al, 2006).

É nesse território em disputa, atravessado por múltiplas concepções e práticas de formação, situado em muitos lugares entre essas duas extremidades - de uma formação centrada no conhecimento, de outra centrada no sujeito - que o PIBID lança suas raízes, como política que possui uma formulação expressa e explícita, mas que certamente permite múltiplas apropriações. E é também nesse sentido, por fim, que talvez não se possa falar da existência de um único PIBID, mas de tantos quantos forem os modos de se fazer formação de professores no ambiente das universidades brasileiras.

\section{O PIBID como política pública de formação docente}

Mas o que é isto, o PIBID, afinal? Ora, trata-se de uma ação estratégica para a formação inicial de professores, implementada sob a forma de um programa de fomento, com bolsas 
específicas para projetos de intervenção direta em práticas escolares. Seu alvo principal é a formação docente nas licenciaturas, mas o modo pelo qual pretende intervir nessa formação supõe o aprofundamento do diálogo entre a universidade e a escola, incentivando as escolas públicas de educação básica a assumirem em parte, pelo menos, o protagonismo nos processos formativos dos futuros professores. De acordo com Gatti (2015, p. 7), é importante observar que "sua vocação é de fomento, não se constituindo em proposta que vise atingir o universo dos licenciandos".

Decorre daí um duplo comentário acerca do PIBID: primeiro, que ele não deve ser considerado como uma ação isolada e gratuita que ocorre nos cursos universitários de graduação, ainda que faça justiça à dimensão do ensino porque, afinal, já existem bolsas de pesquisa, extensão e demanda social. Pelo contrário, o Programa integra uma política nacional de formação de professores para a Educação Básica, sistematizada sobretudo a partir de 2009. Em segundo lugar, o PIBID é fomento, e não propriamente currículo, quer dizer, perpassa a produção simbólica e cultural dos projetos de formação, mas, como sugere Gatti (2015), apenas para aquela pequena parcela de licenciandos que experimentam a condição de bolsistas de iniciação à docência.

Dizer que o PIBID integra uma política nacional de formação inicial e continuada de professores para a Educação Básica significa realçar sua articulação a um contexto instituído a partir da Política Nacional de Formação de Profissionais do Magistério da Educação Básica (Decreto ${ }^{\circ}$ 6.755, 01/2009) e dos Fóruns Estaduais Permanentes de Apoio à Formação Docente (Portaria MEC no 883, de 16/09/2009). O Programa é coerente com o Plano Nacional de Formação dos Professores da Educação Básica - PARFOR (Portaria MEC n 9, de 30/06/2009) e com a formação de uma Rede Nacional de Formação Continuada dos Profissionais do Magistério da Educação Básica Pública (Portaria MEC n 1.328, de 23/09/2011). A Portaria MEC n $n^{\text {0 }}$ 1.087, de 10/08/2011 e a Resolução nº 1, de 17/08/2011 constituem, respectivamente, um Comitê Gestor da Política Nacional e um Comitê Gestor Institucional de Formação de Profissionais do Magistério da Educação Básica como instâncias estratégicas de regulação e de condução da política de formação docente.

Desse modo, o PIBID também consolida o papel estratégico atribuído à CAPES pela Lei $\mathrm{n}^{\mathrm{o}}$ 11.502, de 11 de julho de 2007, que modifica suas competências e sua estrutura organizacional, alterando as leis $\mathrm{n}^{\mathrm{o}}$ 8.405, de 1992, e 11.273, de 2006, inclusive no que se refere à concessão de bolsas de estudo e de pesquisa na formação inicial e continuada de professores 
para a educação básica, um dos pré-requisitos para a instituição do PIBID. O Art. $2^{2}$ da Lei nº 8.405 passa a atribuir à CAPES o papel de subsidiar o Ministério da Educação na formulação de políticas e no desenvolvimento de atividades de suporte à formação de profissionais de magistério para a educação básica e superior. $\mathrm{O} \S 2^{\circ}$ desse mesmo artigo estabelece que, na educação básica,

a Capes terá como finalidade induzir e fomentar, inclusive em regime de colaboração com os Estados, os Municípios e o Distrito Federal e exclusivamente mediante convênios com instituições de ensino superior públicas ou privadas, a formação inicial e continuada de profissionais de magistério, respeitada a liberdade acadêmica das instituições conveniadas.

Por outro lado, se como sugere Gatti (2015), sua vocação é o fomento, o PIBID não participa da formação como componente interno da estrutura curricular dos cursos de licenciatura, permitindo que o estudante possa graduar-se sem que obrigatoriamente participe das atividades do projeto de sua instituição formadora. Adquire sentido, aqui, a advertência, de resto tão comum nos circuitos internos do Programa, segundo a qual "PIBID não é estágio". De fato, enquanto os pareceres e resoluções do Conselho Nacional de Educação que, na virada do século, estabeleceram as diretrizes curriculares para os cursos de licenciatura, instituíram a obrigatoriedade do Estágio Curricular Supervisionado de Ensino (a rigor, já definida anteriormente, inclusive na própria LDB de 1996, que fixou carga horária mínima de 300 horas de atividades), a participação nas atividades do PIBID é voluntária e, mais do que isso, seletiva, na medida em que o número de candidatos ao Programa supera, de uma maneira geral, o número de vagas oferecidas pelo projeto institucional.

Dizendo de outra maneira, enquanto o estágio é um componente curricular permanente e obrigatório da formação, que ao condicionar a conclusão do curso envolve e compromete a totalidade dos licenciandos, o PIBID é um programa específico de indução e fomento, que passa a oferecer às atividades de ensino, na universidade, um valor que antes parecia configurar, de certo modo, atributo exclusivo da pesquisa e da extensão: as bolsas de iniciação à docência. Mais do que um valor econômico, porém, os objetivos do PIBID parecem sinalizar na direção da inversão de valores simbólicos atribuídos ao ensino e às transmissões culturais, à licenciatura como curso de formação profissional, à escola e sua cultura sui generis e, enfim, à profissão docente e ao lugar destinado à prática no núcleo de sua profissionalidade. 
Valorizar a formação significa, nesse sentido, inverter valores no âmbito da cultura universitária. A esse respeito, desde o Decreto $n^{\circ} 7.219 / 2010$ que aparece inscrito entre os objetivos do Programa a necessidade de incentivar a formação de docentes e contribuir para a valorização do magistério, promovendo a integração entre educação superior e educação básica ao inserir os licenciandos no cotidiano de escolas da rede pública de educação, proporcionandolhes oportunidades de criação e participação em experiências de caráter inovador e interdisciplinar, que busquem a superação de problemas identificados no processo de ensinoaprendizagem; paralelamente, incentivar escolas públicas de educação básica e seus professores como co-formadores, protagonistas nos processos de formação inicial para o magistério, contribuindo para a articulação entre teoria e prática e elevando a qualidade das ações acadêmicas nos cursos de licenciatura.

Na versão mais aperfeiçoada do Programa, expressa pela Portaria nº 96, de 18/07/2013, acrescenta-se um novo objetivo que parece reconhecer a originalidade da cultura escolar e do trabalho docente, de modo a justificar o protagonismo dos professores na formação dos pares. Assim, o PIBID deve "contribuir para que os estudantes de licenciatura se insiram na cultura escolar do magistério, por meio da apropriação e da reflexão sobre instrumentos, saberes e peculiaridades do trabalho docente".

Incentivar, contribuir, elevar e inserir são verbos que narram ações afirmativas, implicando sempre em tornar um contexto determinado diferente do estado em que se encontra no momento, no caso, a formação docente, a licenciatura, o magistério e o processo ensinoaprendizagem. O modo como tais ações procuram intervir, no cotidiano das práticas, talvez seja o que importa, de fato, discutir: promovendo a integração entre educação superior e educação básica; proporcionando aos licenciandos a oportunidade de vivenciar experiências de caráter inovador e interdisciplinar, no cotidiano das escolas públicas; mobilizando os professores para que assumam o protagonismo na formação dos futuros pares; aprofundando a articulação entre teoria e prática na licenciatura; e, por fim, inserindo os licenciandos na cultura escolar do magistério, que envolve instrumentos, saberes e peculiaridades do trabalho docente.

\section{Instalação, expansão e aprofundamento do PIBID na UFF}

Embora haja registro de que a UFF tenha se mobilizado para responder ao primeiro edital da Capes, em 2007, por razões diversas o projeto não chegou a ser submetido. Com a 
divulgação de novo edital, em setembro de $2009^{\text {ii }}$, o PIBID da UFF é aprovado com sete subprojetos: Biologia, Física, Matemática, Química, Língua Portuguesa, Pedagogia (Niterói) e Matemática (Santo Antônio de Pádua). A Portaria nº 72, de abril de 2010, flexibiliza a restrição e amplia as áreas contempladas pelo Programa, expediente que será finalmente suprimido pelo Decreto $n^{\circ} 7.219$, de junho do mesmo ano. Logo no início de 2011 a CAPES divulga novo edital ${ }^{\mathrm{iii}}$, convocando as instituições para que apresentem novos projetos, sem prejuízo dos projetos já em andamento. Sem prioridades quanto aos cursos e com limites que passam a ser apenas financeiros, admitindo-se a submissão de propostas de todas as licenciaturas, o novo Projeto da UFF é aprovado com doze subprojetos: Biologia, Física, Matemática, Química, Língua Portuguesa, Pedagogia, História, Geografia, Filosofia, Ciências Sociais, Educação Física (Niterói) e Pedagogia (Santo Antônio de Pádua).

Em março de 2012, com o objetivo de orientar a sistemática de fomento, preservar a continuidade das ações e ampliar o número de beneficiários, a Portaria $n^{\circ} 21^{\text {iv }}$ prorroga a vigência do Projeto de 2009 até julho de 2013, e logo em seguida a CAPES lança novo edital ${ }^{v}$ recebendo propostas de ampliação ou redução dos projetos vigentes. A UFF acrescenta mais 16 subprojetos em três campi: Ciências Biológicas, Ciências Sociais, Educação Física, Filosofia, Física, Geografia, História, Letras-Espanhol, Letras-Inglês, Letras-Português, Matemática, Pedagogia, Química, em Niterói; Matemática, Pedagogia, em Santo Antônio de Pádua; e Química em Volta Redonda. Por fim, nos termos da Portaria n ${ }^{\circ}$ 96, de julho, e do Edital $n^{\circ} 61$, de agosto de 2013, o Programa adquire, na UFF, seu perfil e dimensão atuais ${ }^{\text {vi }}$, com 25 subprojetos em execução: Artes Visuais-Cinema, Biologia (4), Ciências Sociais (4), Educação Física (3), Filosofia (2), Física, Geografia (3), História (4), Interdisciplinar (2), Letras-Espanhol (2), Letras-Francês, Letras-Inglês, Letras-Português (3), Matemática (3), Pedagogia (5), Química (2), em Niterói; Ciências (2), Física, Informática, Pedagogia (3), em Santo Antônio de Pádua; Pedagogia (5), em Angra dos Reis; Ciências Sociais (2), Geografia (2), História (3), em Campos dos Goytacazes; Química (2), em Volta Redonda. Os subprojetos desdobram-se entre 62 Coordenadores de Área, com 166 Supervisores nas escolas, 908 Licenciandos e 5 Coordenadores Institucionais, totalizando 1141 bolsas $^{\mathrm{vii}}$.

Finalmente, no contexto do ajuste fiscal anunciado pelo governo, sobretudo no final de 2015, a CAPES anuncia a meta de reduzir em 50\% o número de bolsas do Programa. O Fórum Nacional dos Coordenadores Institucionais do Programa Institucional de Bolsa de Iniciação à Docência - FORPIBID (2016) vem a público, por intermédio de uma Carta em Defesa do 
PIBID, datada de janeiro de 2016, lembrar o nível de aprofundamento institucional-legal atingido pelo Programa. De acordo com o documento:

O êxito do PIBID e PIBID Diversidade deu ensejo a mudanças na legislação educacional, responsabilizando o governo com a manutenção dos Programas. O Plano Nacional de Educação (Lei $n^{\circ}$ 13.005/2014) institui metas para a formação de professores, incluindo a estratégia de ampliar o PIBID como uma das medidas sistêmicas para a melhoria da qualidade da educação pública em todos os níveis e modalidades. A Lei de Diretrizes e Bases da Educação Nacional (alterada pela Lei ${ }^{\circ} 12.796 / 2013$ ) estabelece o incentivo à formação de profissionais "mediante programa institucional de bolsa de iniciação à docência aos licenciandos" e as Diretrizes Curriculares Nacionais para a Formação de Professores (Resolução CNE/CP n ${ }^{\circ}$ 02/2015) exigem reformas nas licenciaturas, aproximando-as das características e dimensões da iniciação à docência realizadas pelos Programas.

\section{O PIBID e os modos de fazer iniciação à docência}

Daquilo que cada um faz o que é que se escreve?

(Certeau, 2011, p. 100.)

Após essa longa digressão institucional, voltemos ao PIBID real, isto é, àquelas apropriações teóricas e práticas que diferentes sujeitos retiram dos projetos e das prescrições para o dia-a-dia das experiências escolares e universitárias. Já se disse que tanto o ambiente diverso das diferentes instituições formadoras quanto as múltiplas tradições formativas das áreas de conhecimento podem engendrar muitos PIBIDs, o que parece refletir justamente sua riqueza, e não algum defeito pelo desvio de um PIBID essencial. Não obstante, isso não nos dispensa de uma reflexão sobre toda essa multiplicidade de experiências e modos de fazer iniciação à docência.

Em fins de novembro de 2014, quando se preparava para encerrar o primeiro ano de trabalho da versão inaugurada pela Portaria Capes nº 96/2013, a Coordenação Institucional do PIBID UFF reuniu cerca de 30 coordenadores de área para uma avaliação. A eles, pediu-se que narrassem suas experiências a partir de dois eixos principais: (i) como organizamos nossas ações e (ii) como realizamos a formação. As narrativas oscilavam entre situações polares, desde um ufanismo deslumbrado pelo que conseguiam fazer, até o estarrecimento com os obstáculos interpostos pela rotina reprodutora da escola. De uma maneira geral, talvez não fosse impossível 
perceber o predomínio de uma concepção geral segundo a qual, no PIBID, fazíamos algo para a escola, e não exatamente com a escola, repercutindo uma distância, digamos, colonizadora.

Um coordenador da área científica comentou que, diante da insatisfação dos licenciandos pela ausência de um trabalho mais consistente com os conteúdos da ciência, teria dito a eles: "Gente, essa é a nossa realidade"! Outro coordenador, da área de humanidades, avaliou que "nós estamos fazendo coisas, o problema é o impacto disso na escola". Em ambas as falas, para além de inegáveis juízos de valor a respeito da diferença representada pelo trabalho escolar, parece evidente uma perspectiva segundo a qual a universidade teria sido chamada para virar o jogo jogado na escola, de um ensino muito ruim e, talvez pior, refratário às boas práticas, em direção a uma outra lógica, que afirmasse a necessidade de sua aproximação aos saberes e práticas de perfil mais acadêmico. Mas, afinal, o PIBID é uma política de reparação ou um programa de iniciação à docência?

O problema apontado acima parece sugerir a necessidade de ampliar a reflexão em torno das finalidades do PIBID, sobretudo pela consideração de que contribuir a curto e médio prazo para aprimorar a qualidade da educação básica pública, por um lado, e melhorar a formação inicial de professores pelo aprofundamento do diálogo com a escola, por outro, não sejam coisas excludentes. Um dos eixos dessa reflexão pode emergir da compreensão de que o Programa promove, na verdade, uma tríplice formação profissional: inicial, dos próprios licenciandos, pela mediação concreta do ambiente escolar; continuada, dos professores da escola, revendo saberes experienciais e consolidando a condição de formador de campo; também continuada, dos formadores universitários, restaurando a conexão e o sentido da escola como horizonte do seu trabalho.

Tal perspectiva parece ir ao encontro daquela sugestão de Nóvoa (2011), mencionada mais acima, quando propõe passar a formação de professores para dentro da profissão. Por outro lado, enfrentar um discurso sempre detrator com relação à escola pela compreensão do que ela é, mesmo que tensionada, claro, pela perspectiva do que ela também pode vir ser, na contramão de uma perspectiva messiânica e salvacionista da relação entre universidade e escola, parece ser um desafio importante para a contribuição que o PIBID tem a oferecer à formação que empreende pela via da iniciação à docência. O diálogo ainda parecer ser a melhor solução: quem melhor do que os professores, os alunos e suas famílias, para dizerem o que é a escola, mesmo que, como afirma Maria Teresa Esteban (2010), não exista uma história única no conflito de culturas que a constitui. 
Melhor seria, pois, que a universidade se colocasse numa perspectiva de crítica solidária com relação à escola, sobretudo no sentido de dispor um discurso e uma imaginação criativa a serviço da busca de caminhos e soluções alternativas.

\section{O PIBID como estratégia dialógica de formação}

Seminários e oficinas integram uma semântica bem-sucedida das práticas universitárias, mas poder-se-ia dizer o mesmo, necessariamente, em relação à ars exponendi característica da cultura escolar, de que fala Jean-Claude Forquin (1992, p. 33), na perspectiva de uma distância necessária entre a prática de ensino e da prática "da qual ela é o ensino"? Interdisciplinaridade e produção de materiais didáticos inovadores, por outro lado, costumam se apresentar como uma espécie de horizonte que a contribuição da universidade estabelece para a superação dos velhos objetos e das rotinas escolares, mas a prova de fogo deve continuar sendo o modo como tudo isso pode ser incorporado pelas práticas docentes e discentes no cotidiano da escola, depois que os sujeitos da universidade retornam aos seus ambientes de origem.

Compartilhado, sim; apropriado, não. Essa parece ser uma lógica necessária ao PIBID como programa de iniciação à docência, articulando universidade e escola em uma estratégia dialógica de formação: não somente a escola, nem somente a universidade. É nesse sentido que pode ser compreendida, talvez, a afirmação de Yves Chevallard, a respeito das relações entre prescrições externas e fabricação didática no interior das salas de aula, segundo a qual "alguns dos mais belos achados da noosfera não resistem ao jogo da transposição interna" (apud Gabriel, 2001, p. 6). Também este pode ser o significado implícito na observação de António Nóvoa (2011, p. 541), segundo a qual o lugar da pesquisa na educação e na formação docente deve estar, ao mesmo tempo, "na proximidade e na distância com as práticas profissionais".

Para além de uma formação que segue, em suas linhas gerais, aquele modelo caracterizado a partir do foco no conhecimento, os diferentes cursos costumam observar tradições particulares que se materializam em práticas curriculares específicas. No caso da UFF, por exemplo, parece não existir formalmente um projeto institucional de formação docente, senão aquele desenho geral para as licenciaturas, estabelecido pela Resolução CEP nº 50/2004, que não faz muito mais do que definir, para efeitos práticos, uma leitura interna das resoluções $\mathrm{n}^{\circ} 1$ e 2, de 2002, do CNE (Brasil, 2002). Lidas e relidas no âmbito dos cursos segundo chaves de leitura de diferentes tradições, dominantes no âmbito das associações científicas, de 
educação e/ou de ensino (educação em ciências, ensino de história etc), refletem concepções em disputa e equilíbrios precários acerca da formação de professores também no interior dessas mesmas áreas.

Daí porque, mais uma vez, melhor seria se referir não a um, mas a vários PIBIDs dentro do PIBID.

\title{
Protagonismo compartilhado no PIBID História UFF
}

Uma jovem estudante do curso de História da UFF inicia-se na experiência profissional do magistério, ainda um pouco antes da formatura. Assim ela registra nas redes sociais sua primeira vez em sala de aula:

\begin{abstract}
Pensei em escrever algo sobre o dia de hoje como forma de deixar registrado essa memória para que no futuro o Facebook me lembre disso. Certamente quem segue lendo isso já sabe dessa história que contei pessoalmente, por telefone ou mensagem, porque não consegui conter a enxurrada de sentimentos e sensações que eu tive após sair da primeira aula em que eu realmente pude "ser professora". Pode ser que daqui a alguns anos eu leia isso e pense que eu realmente não sabia de nada (fato, rs). Mas espero (com todas as minhas forças) que eu ainda tenha a mesma sensação desse dia que já está tão bem marcado para mim. Hoje senti e confirmei, com experiências positivas e negativas, que a mudança que eu acredito e espero que realmente aconteça, se dá nesse espaço de convivência, troca, diálogo, estresse, mais um pouco de diálogo, desentendimentos, estresse de novo, entendimentos e muito mais diálogo.
\end{abstract}

Diante do comentário de incentivo de uma colega de curso, ao que parece tocada pela experiência larrosiana por que passa no PIBID e certamente reconhecida pela mensageira como alguém que narra e compartilha essa experiência nos espaços de convivência, no dia-a-dia da formação, Maria Julia prossegue:

Parece clichê, mas ver a mobilização de vocês em PIBID, nos coletivos e nos debates em sala, foi muito importante para mim, que recusei a ideia de ser professora por conta dos estereótipos em torno da profissão. De alguma forma você e algumas pessoas do curso são responsáveis por isso.

Seria quase óbvio reproduzir aqui depoimentos de bolsistas, estudantes que estão ou que estiveram formalmente vinculados ao PIBID. A importância do registro acima, no entanto, se prende ao fato de que o Programa ultrapassa os limites individuais da experiência de iniciação 
à docência para alcançar o convívio que forma na informalidade dos relatos e das trocas em cada ocasião. Muito óbvio, também, seria a transformação do espaço deste texto num repositório de ações - projetos, oficinas, produtos, intervenções - que demonstrasse toda a riqueza e a capacidade inventiva posta à serviço da formação, ainda que a construção e o registro de um repertório de professor nunca possam ser considerados nem excessivo, nem supérfluo. No fundo, o Programa tem sido fértil também no registro e compartilhamento dessas invenções didáticas, inovadoras não porque sejam feitas pela universidade para, mas porque de algum modo contemplam a perspectiva $d a$ escola.

Fosse o caso de trazer tais registros à luz da exposição e ao (re)conhecimento público, para além do que ocorre aos próprios licenciandos, professores da escola e da universidade em múltiplos percursos de formação inicial e continuada, melhor seria exibir as quantidades em jogo no Projeto de História ${ }^{\text {viii }}$, ou remeter a esse registro de alguns relatos sob a forma de breves artigos reunidos no livro "Universidade e escola formando professores de História". Relatando uma ação semelhante àquela apresentada no início deste texto, assim se expressam os autores de um texto incluído na obra (Nascimento et al, 2015, p. 23):

O projeto Roda de Leituras Históricas emerge em meio a um cotidiano escolar que nos revelou a necessidade de investirmos em alternativas pedagógicas diferenciadas daquelas que se restringem ao trabalho de apresentação de conteúdos definidos no currículo mínimo, buscando ampliar a compreensão dos estudantes sobre os temas trabalhados em sala de aula a partir da leitura de diferentes gêneros literários, considerando a urgência em garantir a imersão no mundo da palavra, não apenas como aquele que observa, fala ou lê, mas enquanto sujeito que se relaciona com a língua escrita de forma autônoma e que também produz textos (re)significando o mundo em que vive.

Em meio à grande diversidade de ações implementadas e de significados construídos, importa dizer, finalmente, que o PIBID é, antes de mais nada, um programa voltado para a formação docente: destina-se, prioritariamente, aos estudantes inscritos em cursos universitários de formação de professores. Traz implícita, porém, a compreensão de que a universidade sozinha não dá conta dessa formação: ela precisa da escola e dos professores que estão na escola, futuro antecipado, em certa medida, aos licenciandos. Mas também a melhoria da qualidade da escola pública e do trabalho de seus professores deve estar comprometido no Programa. Por isso, não são apenas os estudantes que estão em formação, mas também os professores se encontram em processo de formação continuada, revisando conteúdos e métodos, 
repensando teórica, prática e politicamente os problemas da profissão e atualizando sua própria condição de formadores dos professores, seus futuros pares.

Por fim, também a qualidade dos cursos universitários de formação docente precisa ser repensada - e aqui está o terceiro compromisso do PIBID. Nesse caso, trata-se de rever o papel dos professores universitários, aprofundando suas relações de parceria e diálogo com a escola básica e seus profissionais, iniciando também um movimento de formação continuada, em sua condição de formadores de professores. Mas é preciso reconhecer que não se trata de mero investimento quantitativo numa concepção tradicional de formação como relação linear e unívoca entre um formador e um formando: trata-se de um processo circular em que todos se formam, formando-se mutuamente. A este movimento de ações recíprocas entre os sujeitos corresponde o sentido de se dizer que o PIBID consiste num movimento de trans/formação, ou de protagonismo compartilhado, reconhecendo as múltiplas formas pelas quais cada qual assume suas responsabilidades e seu compromisso com esse contexto formativo.

As experiências em curso no Projeto de História, como de resto em todo o PIBID na UFF, reiteram a compreensão de que o caminho se faz ao caminhar, rumo a um novo olhar sobre a escola e a docência, na perspectiva da formação. Os problemas e as dificuldades cotidianas, particularmente nesses tempos difíceis por que atravessa a sociedade brasileira, não paralisam a crença na possibilidade de construção de alternativas que contribuam para uma educação pública de qualidade para todos.

\section{Referências}

ANDRADE, Everardo Paiva de Andrade; ALMEIDA, Juniele Rabêlo de; CABECEIRAS, Manuel Rolph de Viveiros; DEZEMONE, Marcus Ajuruam de Oliveira. PIBID. Relatório de atividades 2015. Niterói - RJ: PROGRAD / UFF, 2015. 87 p.

ANDRADE, Everardo Paiva de; ALMEIDA, Juniele Rabêlo de; CABECEIRAS, Manuel Rolph de Viveiros; DEZEMONE, Marcus Ajuruam de Oliveira. PIBID. Universidade e escola formando professores de História. São Paulo - SP: Letra e Voz, 2015. 230 p.

ANDRADE, Oswald de. Memórias sentimentais de João Miramar. $3^{\text {a }}$ ed., Rio de Janeiro RJ: Civilização Brasileira, 1971. Disponível em http://www.aedi.ufpa.br/parfor/letras/images/documentos/atividadesadistancia_jan2016/Franc isco_ewerton/memorias_sentimentais_de_joao_miramar_-_\%20oswald_\%20de_andrade.pdf. Acesso em 27/06/2016. 
BRASIL. Resolução CNE/CP no 1, de 18/02/2002. Brasília - DF: Conselho Nacional de Educação, 2002. Disponível em http://portal.mec.gov.br/cne/arquivos/pdf/rcp01_02.pdf. Acesso em 28/02/2016.

CERTEAU, Michel de. A invenção do cotidiano, 1. Artes de fazer. $17^{\mathrm{a}}$ ed., Petrópolis - RJ: Vozes, 2011. 320 p.

CONTRERAS, José. A autonomia de professores. São Paulo - SP: Cortez, 2002. 296 p. ESTEBAN, Maria Teresa. Diferença, aprendizagens e avaliação: perspectiva pós-colonial e escolarização. In: AFONSO, Almerindo Janela; ESTEBAN, Maria Teresa (Orgs.). Olhares e interfaces: reflexões críticas sobre a avaliação. São Paulo - SP: Cortez, 2010. 176 p.

FORQUIN, J.C. Saberes escolares, imperativos didáticos e dinâmicas sociais. In: Teoria e Educação, 5. Porto Alegre: Pannonica, 1992. p. 28-49.

GABRIEL ANHORN, Carmen Teresa. Usos e abusos do conceito de transposição didática: considerações a partir do campo disciplinar da História. In: Anais do IV Seminário Perspectivas do Ensino de História. Ouro Preto - MG: IV SPEH, 2001. 6 p. Disponível em http://www.vdl.ufc.br/solar/aula_link/lmat/A_a_H/didatica_I/aula_045120/imagens/01/usos_abusos_transposicao_didatica.pdf. Acesso em 27/06/2016

GABRIEL, Carmen Teresa Anhorn. Usos e Abusos do conceito de transposição didática; considerações a partir do campo disciplinar de História. In: Anais do IV Seminário Perspectivas do Ensino de História. Ouro Preto: 2001. 5 p.

GATTI, Bernadete. Formação de professores: licenciaturas, currículos e políticas. In: Movimento - Revista de Educação, nº 2. Niterói - RJ: FEUFF / PPGE, 2015. 18 p.

GAUTHIER, C. et al. Ensinar: ofício estável, identidade profissional vacilante. In: Por uma teoria da pedagogia: pesquisas contemporâneas sobre o saber docente. $2^{\mathrm{a}}$ ed., Ijuí: Edunijuí, 2006. p. 17-37.

MONTEIRO, Ana Maria. A prática de ensino e a produção de saberes na escola. In:

CANDAU, Vera Maria (Org.). Didática, currículo e saberes escolares. Rio de Janeiro - RJ: DP\&A, 2000. p. 129-147.

NASCIMENTO, Priscila Artte Rosa; GUBANI, Alexandre; SILVA, Alexandre de Oliveira; MACHADO, Antônio Felipe da Costa Monteiro; ARAÚJO, Caroline Pereira Barros; OLIVEIRA, Ramon Ruben Peixoto de; HARTHE, Wagner Luiz Nogueira. Formação docente e construção de alternativas pedagógicas: o ensino de História no âmbito do PIBID. In: ANDRADE, Everardo Paiva de; ALMEIDA, Juniele Rabêlo de; CABECEIRAS, Manuel Rolph de Viveiros; DEZEMONE, Marcus Ajuruam de Oliveira. PIBID. Universidade e escola formando professores de História. São Paulo - SP: Letra e Voz, 2015. p. 21-26.

NÓVOA, António et al. Pesquisa em educação como processo dinâmico, aberto e imaginativo: uma entrevista com António Nóvoa. Educação \& realidade, v. 36, n. 2. Porto Alegre - RS, maio/agosto 2011. p. 533-543. 
TARDIF, Maurice. Saberes, tempo e aprendizagem do trabalho no magistério. In: Saberes docentes e formação profissional. Petrópolis - RJ: Vozes, 2002. p. 56-11.

\footnotetext{
${ }^{\text {i }}$ Professor Adjunto do Programa de Pós-Graduação em educação (PPGE) da Faculdade de Educação da UFF (FEUFF) e também do PROFHISTÓRIA - Mestrado Profissional em Ensino de História, Pesquisador do CDC Grupo de Pesquisa Currículo, Docência \& Cultura e do LEH - Laboratório de Ensino de História, ambos sediados na FEUFF.

ii Disponível em https://www.capes.gov.br/images/stories/download/bolsas/Edital02_PIBID2009.pdf

iii Disponível em https://www.capes.gov.br/images/stories/download/bolsas/Edital_001_PIBID_2011.pdf

iv Disponível em https://www.capes.gov.br/images/stories/download/legislacao/Portaria21-

12mar12_ProrrogacaoVigenciaProjetosPibid.pdf

${ }^{v}$ Disponível em https://www.capes.gov.br/images/stories/download/bolsas/Edital_011_Pibid-2012.pdf

vi Disponíveis, em https://www.capes.gov.br/images/stories/download/legislacao/Portaria_096_18jul13_AprovaRegulamentoPIBID .pdf e https://www.capes.gov.br/images/stories/download/editais/Edital_061_2013_PIBID.pdf

vii Fonte: Editais da CAPES e Coordenação Institucional do PIBID UFF.

viii No relatório de 2014 consta, além dos 4 Coordenadores de Área, 12 Supervisores e 62 Licenciandos, todos bolsistas do Projeto PIBID História UFF, cerca de dez colaboradores não vinculados ao Programa e um número em torno de 2500 alunos da educação básica envolvidos em 75 atividades realizadas no projeto, gerando 170 produções didático-pedagógicas, 37 produções bibliográficas, 21 produções artístico-culturais e 6 produções lúdicas.
} 